\title{
Cyclic Injection to Enhance Hydraulic Fracturing Efficiency: Insights from Laboratory Experiments
}

\author{
Hao Kang $\mathbb{D},{ }^{1}$ Jincai Zhang $\mathbb{D},{ }^{2}$ Xin Fan, ${ }^{3}$ and Zhiwen Huang ${ }^{3}$ \\ ${ }^{1}$ Massachusetts Institute of Technology, Cambridge, MA, USA \\ ${ }^{2}$ SINOPEC Tech Houston, Houston, TX, USA \\ ${ }^{3}$ SINOPEC Petroleum Exploration \& Production Research Institute, Beijing, China
}

Correspondence should be addressed to Hao Kang; kangh@mit.edu

Received 27 September 2020; Revised 22 November 2020; Accepted 27 November 2020; Published 11 December 2020

Academic Editor: Xiaorong Li

Copyright (c) 2020 Hao Kang et al. This is an open access article distributed under the Creative Commons Attribution License, which permits unrestricted use, distribution, and reproduction in any medium, provided the original work is properly cited.

In hydraulic fracturing applications, there is substantial interest to reduce the formation breakdown pressure. Previous research results show that the cyclic injection method can be used to reduce that pressure. In this study, we conducted laboratory hydraulic fracturing experiments to apply cyclic injection to reduce the breakdown pressures of very tight and strong sandstones. Experimental results show that using cyclic injection the average breakdown pressure was reduced by $18.9 \%$ in very tight sandstones and by $7.18 \%$ in normal sandstones. This indicates that the effect of cyclic injection is more significant for stronger and tighter rocks. The experiments also reveal that the rock tensile strength plays a more important role in the formation breakdown pressure with a rock strength factor of 2.85. This suggests that the breakdown pressure is higher than expected. In addition, we empirically related the breakdown pressure reduction and the injection pressure amplitude to the number of injection cycles. The curve fitting results imply that the effect of cyclic injection is more important if the number of cycles or the injection pressure amplitude is increased. Based on the results of this research, the in-situ formation breakdown pressure can be reduced by applying the cyclic injection method, and the breakdown pressure reduction is more significant as the number of cycles increases.

\section{Introduction}

Hydraulic fracturing has become increasingly important for hydrocarbon extraction in sedimentary rocks and enhanced geothermal systems in crystalline rocks [1-3]. However, in some field conditions, the rock is tight and strong, or the tectonic stresses are very high. As a result, the rock cannot be hydraulically fractured easily. Therefore, there is substantial interest in reducing the hydraulic fracturing breakdown pressure.

To reduce the hydraulic fracturing formation breakdown pressure, one commonly used method is cyclic injection. Several research groups have experimentally investigated the effect of cyclic loading on breakdown pressure reduction: Patel et al. [4] and Goyal et al. [5] conducted cyclic injection on sandstone; Zhuang et al. [6] and Zang et al. [7] conducted cyclic injection on granite; and Tariq et al. [8] conducted cyclic injection on concrete. They reported that at laboratory scale, compared to conventional injection in which the injection pressure increases monotonically, the cyclic injection can reduce the breakdown pressure of sandstone $[4,5]$, granite $[6,7]$, and concrete [8]. For example, Zhuang et al. [6] conducted cyclic injection tests on 34 Pucheon granite specimens, and they reported that cyclic injection can reduce the breakdown pressure for granitic rocks by at least $10 \%$. Patel et al. [4] conducted cyclic injection tests on both dry and saturated Tennessee sandstones; they stated that for dry sandstone, cyclic injection can reduce the breakdown pressure by $15 \%$. Tariq et al. [8] conducted cyclic injection tests on concrete specimens with three different strengths. They observed that the effect of cyclic injection is more important on stronger concrete samples, and for strong concrete samples, cyclic injection can reduce the breakdown pressure by $20 \%$. The effect of cyclic injection is dependent 
on several experimental parameters: the number of cycles, injection pressure amplitude (this will be defined later), confining pressure, injection frequency, rock type, etc.

However, it appears that for sandstones, all previous experimental work was conducted on relatively porous specimens. For example, the porosity for the Tennessee sandstone tested by Patel et al. [4] and Goyal et al. [5] is approximately $8.5 \%$. In other words, it appears that no experimental work has been conducted to systematically study the effect of cyclic injection on the breakdown pressure in very tight sandstones. It is very difficult for tight sandstone to be efficiently fractured [9] because of its high breakdown pressure; therefore, the effect of cyclic injection on very tight sandstone is worthwhile to explore.

So far, the effect of cyclic injection on the breakdown pressure has been studied by only a few research groups. In contrast, the effect of cyclic loading, with a similar mechanism to cyclic injection, on the rock strength under dry conditions has been extensively investigated experimentally. Numerous experiments have been conducted to explore the effect of the number of cycles, loading stress amplitude (this will also be defined later), confining pressure, injection frequency, rock type, etc [10]. Based on the results of cyclic loading experiments, Schijve [11] proposed an empirical curve which relates the rock strength reduction to the number of required cycles (S-N curve). Although the data of the S-N curve shows significant scattering, the S-N curve still provides a reference for strength reduction prediction. However, for cyclic injection tests, such an empirical curve has not been proposed yet. If such a relation is present, it could provide a good method to predict the breakdown pressure reduction to guide hydraulic fracturing operations.

The main objectives of this paper are as follows: (1) to systematically investigate the effect of cyclic injection on very tight sandstones and compare the results with normal sandstones and (2) to empirically relate the breakdown pressure reduction to the number of required cycles to provide breakdown pressure prediction. To achieve the two objectives, we first conducted systematic cyclic injection tests on very tight and normal sandstones. The breakdown pressure reduction for two different groups of sandstones was compared. Then, we proposed empirical relationships for cyclic injection from different experiments including the data obtained from publications. The experimental and curve-fitting results will eventually provide a reference for future laboratory-scale experiments under more complicated cyclic loading patterns or field hydraulic fracturing.

\section{Laboratory Testing Methodology}

In this research, the Xujiahe sandstone was used for cyclic injection tests. The experimental methodology and results are explained in detail in Kang et al. [12]. Therefore, in this paper, we briefly recapitulate the experimental methodology and the results.

2.1. Rock Specimens. The experimental large rock blocks were obtained from the outcrops of the Xujiahe sandstones, as

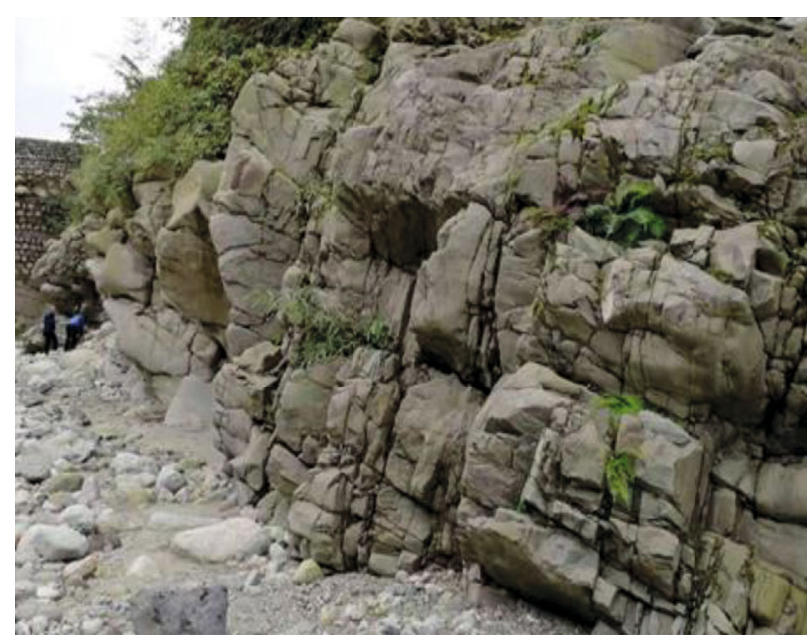

Figure 1: The outcrop of the Triassic Xujiahe sandstones in the Sichuan Province of China.

shown in Figure 1. The Xujiahe group comprises a sequence of sandstone sediments deposited in the area of the present Sichuan Basin, China, between the lower Triassic and upper Jurassic. The Xujiahe sandstone gas reservoirs underlie the Sichuan Basin at a depth of approximately 3000 to 5000 meters, and the outcrops from which we took the rock specimens are located in $31.43325^{\circ} \mathrm{N}, 104.00831^{\circ} \mathrm{E}$. Two batches of sandstone intact specimens were cored from the outcrop. The first batch of sandstone is very tight and strong, with an average permeability of $0.054 \mathrm{mD}$ and a porosity of $1.05 \%$. The second batch of sandstone is not so tight, with an average permeability of $0.32 \mathrm{mD}$ and a porosity of $13.24 \%$.

2.2. Experimental Methodology. For each batch of experiments, cylindrical sandstone specimens were cored from neighboring locations from the same outcrop. After coring, one vertical borehole was drilled along the centerline of each cylindrical specimen for fracturing fluid injection. Figure 2 shows the schematic of the cylindrical specimen with a vertically drilled borehole and the picture of one of the rock specimens.

Each specimen was hydraulically fractured in a triaxial cell system, as shown in Figure 3. In the experiments, 2\% $\mathrm{KCl}$ solution was used as the injection and fracturing fluid. During each test, the axial and confining pressures in the triaxial apparatus were applied first. The axial and confining pressures were fixed at $13 \mathrm{MPa}$ and $8 \mathrm{MPa}$, respectively. After the axial and confining pressures reached these magnitudes, the fracturing fluids were injected and the injection pressure was increased and varied in different experimental scenarios. Two types of experiments were conducted: cyclic injection tests and conventional injection tests.

For cyclic injection tests, two methods were used: stepped pressure injection and constant pressure injection. Figures 4 and 5 explain the methodology for stepped pressure injection and constant pressure injection, respectively. Both methods have two stages: cyclic injection stage and rock breaking stage. In the cyclic injection stage, the pressurization rate 


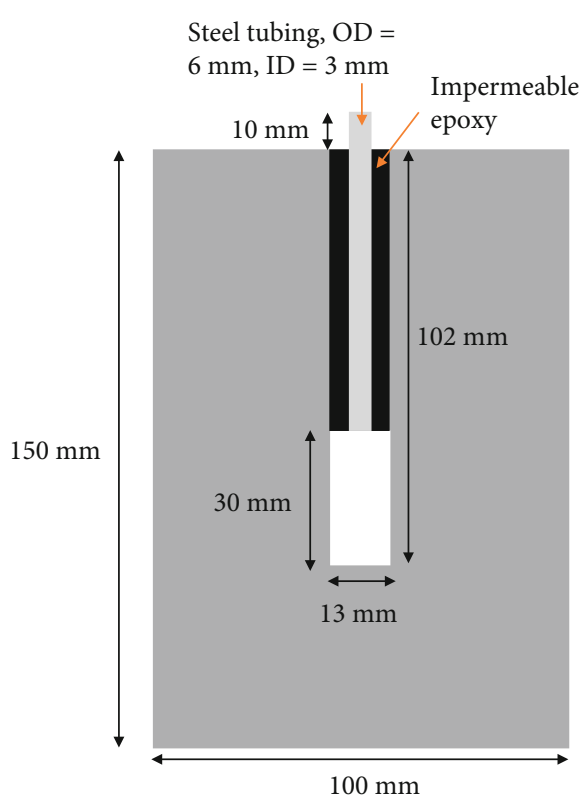

(a)

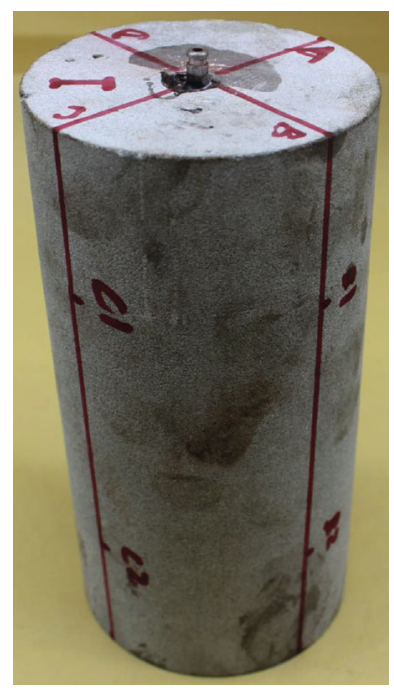

(b)

Figure 2: (a) Schematic of the vertical borehole drilled in each rock specimen for the first batch of sandstone. (b) Picture of one specimen from the second batch of sandstone (diameter: $100 \mathrm{~mm}$; height: $190 \mathrm{~mm}$ ).

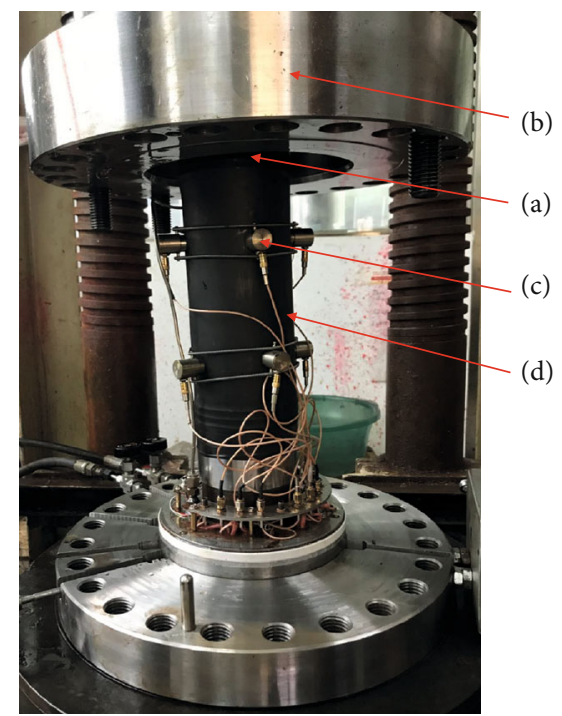

FIgURE 3: Triaxial testing system: (a) top cap for applying axial stress (not visible); (b) confining chamber for applying confining stress; (c) acoustic sensors attached to the sealing tubing; (d) sealing tubing (two layers of heat-shrink tubing).

was fixed at $0.167 \mathrm{MPa} / \mathrm{s}$, the holding time for the reduction was fixed at $30 \mathrm{sec}$, the holding time for increment was fixed at $90 \mathrm{sec}$, and the reduced pressure was fixed at $1.5 \mathrm{MPa}$. In the rock breaking stage, the injection flow rate was fixed at $2.4 \mathrm{~mL} / \mathrm{min}$.

For conventional injection tests, the injection pressure was increased monotonically and the injection flow rate was fixed at $2.4 \mathrm{~mL} / \mathrm{min}$. The created fracture after the rock breakdown in each specimen was the vertical fracture, as predicted. That is, the hydraulic fracture plane created by injection is along the borehole axial direction, as shown in Figure 6.

For each specimen, after the hydraulic fracturing test, one small cylindrical specimen (diameter: $25.4 \mathrm{~mm}$; length: $50.8 \mathrm{~mm}$ ) was cored for a uniaxial compression test, and another small cylindrical specimen (diameter: $25.4 \mathrm{~mm}$; length: $12.7 \mathrm{~mm}$ ) was cored for a Brazilian test. Both cylindrical specimens were cored from the unbroken part of the original specimen.

\section{Laboratory Experimental Results}

3.1. Experimental Results of Breakdown Pressures. Tables 1 and 2 summarize the hydraulic fracturing results for the first batch of sandstone, and Tables 3 and 4 summarize the results for the second batch of sandstone. In the first batch (very tight sandstones), the average breakdown pressure for conventional injection is $43.03 \mathrm{MPa}$ and for cyclic injection is $34.90 \mathrm{MPa}$. This suggests that by using cyclic injection, the breakdown pressure was reduced by $18.9 \%$. In the second batch (normal strength sandstones), the average breakdown pressure for conventional injection is $27.15 \mathrm{MPa}$ and for cyclic injection is $25.20 \mathrm{MPa}$. This suggests that the breakdown pressure was reduced by $7.18 \%$. Figure 7 compares the average breakdown pressures (both conventional and cyclic injections) for the first and second batches.

The results suggest that cyclic loading can reduce the breakdown pressure for sandstones. In addition, the effect of cyclic loading is more significant for reducing the breakdown pressure for stronger and tighter rocks. 


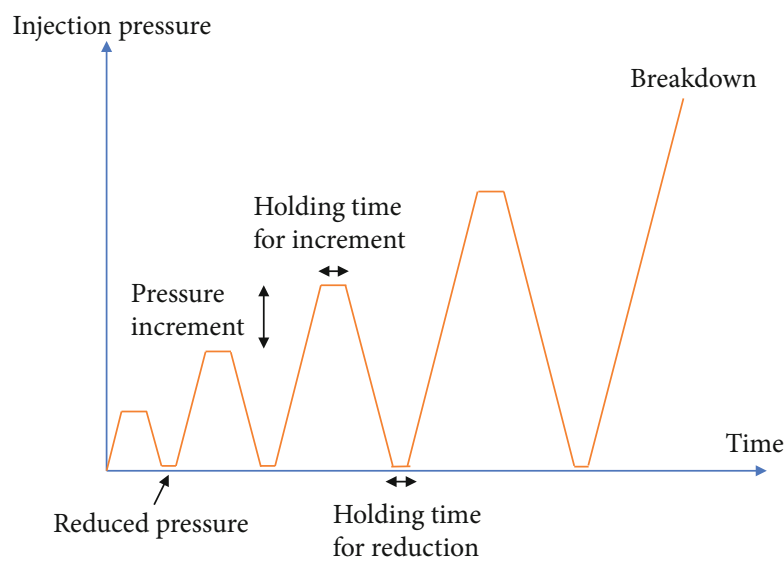

FIGURE 4: Schematic of the stepped pressure injection method in the cyclic injection tests.

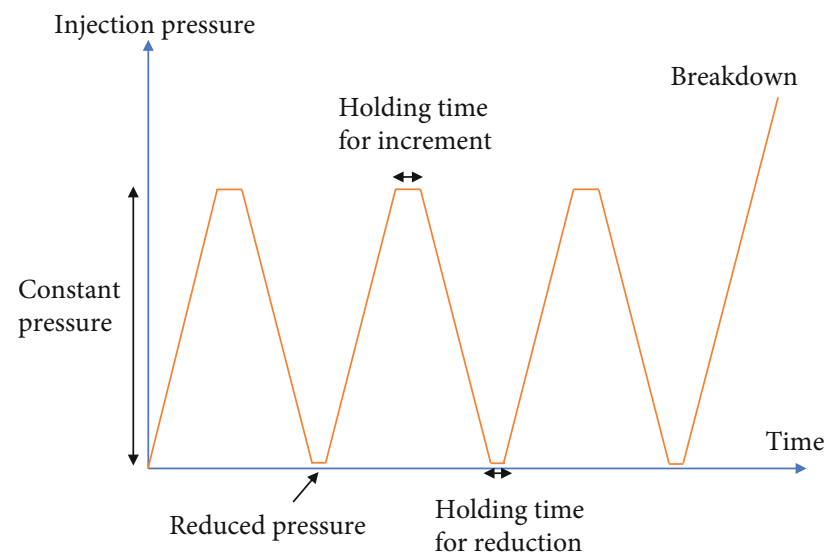

Figure 5: Schematic of the constant pressure injection method in the cyclic injection tests.

3.2. Correlations between Rock Strength and Formation Breakdown Pressure for Conventional Injection Tests. The results in Tables 1 and 3 suggest that for conventional injection tests, the formation breakdown pressure increases as the tensile strength of the rock matrix increases. This trend agrees well with the theoretical equation proposed by Zhang et al. [13] and Zhang [14]:

$$
p_{b}=3 \sigma_{h}-\sigma_{H}-p_{p}+k T,
$$

where $p_{b}$ is the formation breakdown pressure, $\sigma_{H}$ is the maximum horizontal stress, $\sigma_{h}$ is the minimum horizontal stress, $p_{p}$ is the pore pressure, $T$ is the tensile strength, and $k$ is the rock strength factor. Compared with the Haimson and Fairhurst equation [15] which calculates the fracture initiation pressure, Equation (1) predicts the formation breakdown pressure. Here, the $k$ value can be determined for the Xujiahe sandstone. In all conventional injection tests, $\sigma_{H}=$ $\sigma_{h}=$ confining pressure $=8 \mathrm{MPa}$ and $p_{p}=0$. Therefore, by substituting $\sigma_{H}, \sigma_{h}$, and $p_{p}$ into Equation (1), Equation (1)

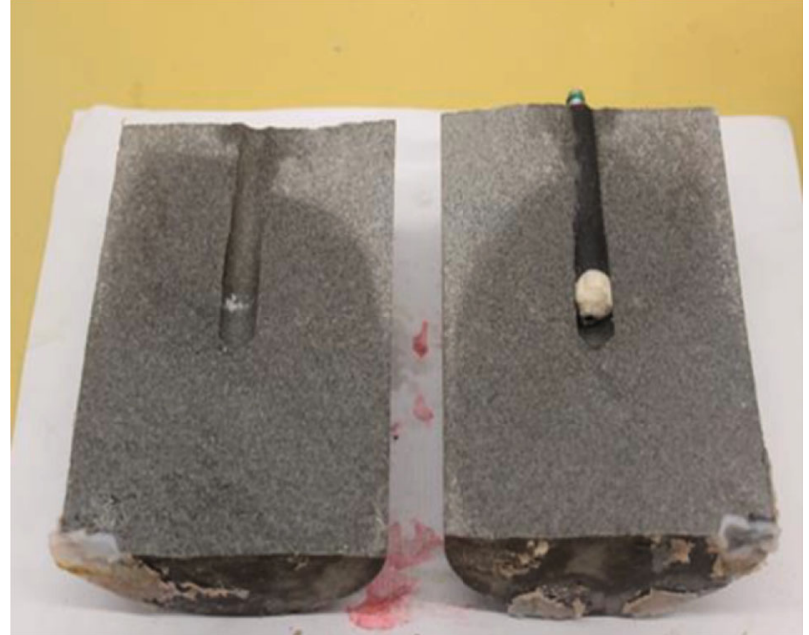

FIGURE 6: The vertical fracture created along the axial direction in a specimen for the first batch.

becomes $p_{b}=(16+k T) \mathrm{MPa}$ and has only one variable. Using the linear curve fitting, the breakdown pressure can be expressed as

$$
p_{b}=16+2.8538 T \text {. }
$$

Figure 8 plots the data points and the fitted line. Equation (2) indicates that the rock tensile strength plays a much more important role in the formation breakdown pressure than expected (i.e., the rock strength factor $k=1$ ). This suggests that for tight rocks, the breakdown pressure is expected to be higher, compared with normal rocks.

\section{Empirical Curve Fitting for Breakdown Pressure Reduction in Cyclic Injection Tests}

4.1. Breakdown Pressure Reduction versus the Number of Cycles. As discussed before, in hydraulic fracturing, cyclic injection can reduce the breakdown pressure $[4,5,12,16]$. One method to quantify the effect of cyclic injection tests is to plot the normalized breakdown pressure (breakdown pressure in cyclic injection/breakdown pressure in conventional injection) versus the number of cycles. Table 5 summarizes the sources of data we used from this experiment and public literature. It appears that cyclic injection tests have been conducted mainly on granite, sandstone, and concrete.

Figure 9 summarizes the data we used for the curve fitting. The red line corresponds to the fitted line based on the cyclic injection test data from Table 5. Here, we compare this cyclic injection fitting curve to the results obtained from the cyclic loading tests, i.e., the dashed line corresponding to the empirical line published by Schijve [11]. Schijve's line plots the normalized cyclic loading strength (strength under cyclic loading/strength under monotonic loading) versus the number of cycles, under dry conditions.

The data points presented in Figure 9 are indeed scattered ( $r^{2}$ of the fitted line is 0.11 ), but the trend is still clear. The breakdown pressure decreases with an increasing 
TABLE 1: Result summary for the first batch of sandstone.

\begin{tabular}{|c|c|c|c|c|c|}
\hline $\begin{array}{l}\text { Specimen } \\
\text { no. }\end{array}$ & $\begin{array}{l}\text { Injection } \\
\text { method }\end{array}$ & $\begin{array}{c}\text { Injection flowrate or injection } \\
\text { pressure }\end{array}$ & $\begin{array}{l}\text { Breakdown pressure } \\
(\mathrm{MPa})\end{array}$ & $\begin{array}{c}\text { Tensile strength } \\
(\mathrm{MPa})\end{array}$ & $\begin{array}{c}\text { Compressive strength } \\
(\mathrm{MPa})\end{array}$ \\
\hline 1 & Conventional & $2.4 \mathrm{~mL} / \mathrm{min}$ & 43.09 & 9.282 & 172.85 \\
\hline 2 & Conventional & $2.4 \mathrm{~mL} / \mathrm{min}$ & 38.42 & 8.455 & 150.84 \\
\hline 3 & Conventional & $2.4 \mathrm{~mL} / \mathrm{min}$ & 47.59 & 11.611 & 152.73 \\
\hline 4 & $\begin{array}{l}\text { Stepped } \\
\text { pressure }\end{array}$ & $4-8-12-16-20-24 \mathrm{MPa}$ & 29.03 & 10.010 & 171.02 \\
\hline 5 & $\begin{array}{l}\text { Constant } \\
\text { pressure }\end{array}$ & $20 \mathrm{MPa}$ & 31.53 & 9.148 & 157.51 \\
\hline 6 & $\begin{array}{l}\text { Constant } \\
\text { pressure }\end{array}$ & $25 \mathrm{MPa}$ & 42.75 & 10.498 & 164.90 \\
\hline 7 & $\begin{array}{l}\text { Constant } \\
\text { pressure }\end{array}$ & $25 \mathrm{MPa}$ & 36.28 & 8.690 & 153.56 \\
\hline
\end{tabular}

TABLE 2: Some average results for the first batch of sandstone.

\begin{tabular}{lcc}
\hline Parameter & Conventional injection & Cyclic injection \\
\hline Averaged breakdown pressure (MPa) & 43.03 & 34.90 \\
Standard deviation of the breakdown pressure (MPa) & 3.74 & 5.23 \\
Averaged uniaxial compressive strength (MPa) (all 7 specimens) & 160.49 \\
Averaged Brazilian tensile strength (MPa) (all 7 specimens) & 9.67 \\
\hline
\end{tabular}

TABLE 3: Results summary for the second batch of sandstone.

\begin{tabular}{|c|c|c|c|c|c|}
\hline $\begin{array}{l}\text { Specimen } \\
\text { no. }\end{array}$ & $\begin{array}{l}\text { Injection } \\
\text { method }\end{array}$ & $\begin{array}{l}\text { Injection flowrate or injection } \\
\text { pressure }\end{array}$ & $\begin{array}{l}\text { Breakdown pressure } \\
(\mathrm{MPa})\end{array}$ & $\begin{array}{l}\text { Tensile strength } \\
(\mathrm{MPa})\end{array}$ & $\begin{array}{l}\text { Compressive strength } \\
(\mathrm{MPa})\end{array}$ \\
\hline 1 & Conventional & $2.4 \mathrm{~mL} / \mathrm{min}$ & 18.35 & 2.819 & 47.64 \\
\hline 2 & Conventional & $2.4 \mathrm{~mL} / \mathrm{min}$ & 26.70 & 2.362 & 48.93 \\
\hline 5 & Conventional & $2.4 \mathrm{~mL} / \mathrm{min}$ & 36.40 & 2.557 & 46.92 \\
\hline 3 & $\begin{array}{l}\text { Stepped } \\
\text { pressure }\end{array}$ & $2-4-6-8-11-13-15-17 \mathrm{MPa}$ & 25.36 & 1.785 & 48.76 \\
\hline 4 & $\begin{array}{l}\text { Stepped } \\
\text { pressure }\end{array}$ & $2-4-6-8-11-13-15-17 \mathrm{MPa}$ & 26.10 & 1.614 & 44.07 \\
\hline 6 & $\begin{array}{l}\text { Constant } \\
\text { pressure }\end{array}$ & $16 \mathrm{MPa}$ & 24.13 & 2.245 & 54.28 \\
\hline
\end{tabular}

TABLE 4: Some average results for the second batch of sandstone.

\begin{tabular}{lcc}
\hline Parameter & Conventional injection & Cyclic injection \\
\hline Averaged breakdown pressure (MPa) & 27.15 & 25.20 \\
Standard deviation of the breakdown pressure (MPa) & 7.38 & 0.81 \\
Averaged uniaxial compressive strength (MPa) (all 6 specimens) & 48.43 \\
Averaged Brazilian tensile strength (MPa) (all 6 specimens) & 2.23 \\
\hline
\end{tabular}

number of cycles. The normalized breakdown pressure can be related to the number of cycles as

$$
\frac{P_{\text {cyc }}}{P_{\text {con }}}=-0.009878 \ln N+0.9097 \text {, }
$$

where $N$ is the number of cycles, $P_{\text {cyc }}$ is the breakdown pressure in cyclic injection, and $P_{\text {con }}$ is the breakdown pressure in conventional injection. It is worth noting that the red line is below the dashed line, which indicates that compared with dry cyclic loading, cyclic injection (by fluid pressure) has a stronger effect on the strength reduction. In addition, most sandstone data points and all concrete data points are below Schijve's line, while some granite data points are above Schijve's line. This indicates that the effect of cyclic injection may be dependent on the rock type. 


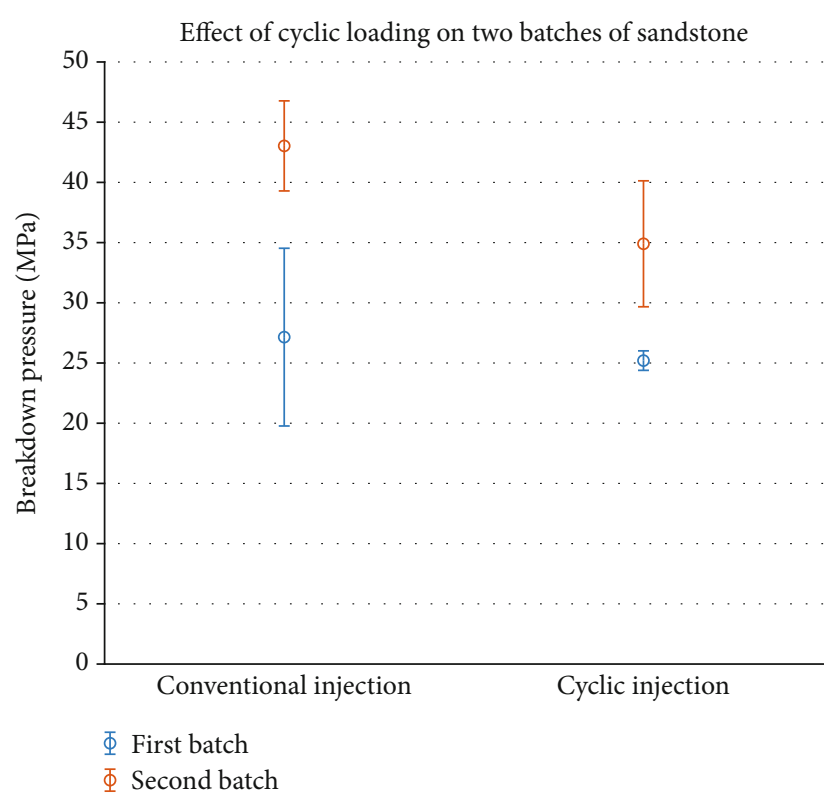

FiguRe 7: Average breakdown pressures for the first and second batches of sandstone. The error bars represent the standard deviation of each category.

For concrete and sandstone, the amount of available data is very limited, and the number of cycles $N$ falls into a very narrow range (between 5 and 12). Therefore, we also tried to plot the data only for granite, and Figure 10 summarizes the results for granite. The red line corresponds to the fitted line based on the cyclic injection data from Table 5 (granite only), and the dashed line corresponds to Schijve's line [11].

Similar to those in Figure 9, the data points shown in Figure 10 are scattered $\left(r^{2}\right.$ of the fitted line is 0.15$)$, but they have a visible trend. The breakdown pressure decreases with an increasing number of cycles. The normalized breakdown pressure of granite can be related to the number of cycles as

$$
\frac{P_{\text {cyc }}}{P_{\text {con }}}=-0.01246 \ln N+0.9255 \text {. }
$$

Equation (4) is obtained from the results of granite only, while Equation (3) is obtained from the results of granite, sandstone, and concrete. For granite, compared with dry cyclic loading, cyclic injection (by fluid pressure) has a stronger effect on the breakdown pressure (strength) reduction.

The amount of cyclic injection data is limited. As a result, between different data points in Figures 9 and 10, the injection pressure, injection frequency, and the confining pressure are different. In reality, the effect of cyclic injection can be strongly dependent on the above-mentioned experimental parameters, even for the same rock type. Therefore, if more data are available in the future, more reliable curves under each experimental condition could be fitted.

4.2. Injection Pressure Amplitude at each Cycle versus the Number of Cycles. In fatigue analysis of metals, loading stress amplitude applied during cyclic loading is often related to the required number of cycles to failure. Figure 11 illustrates the

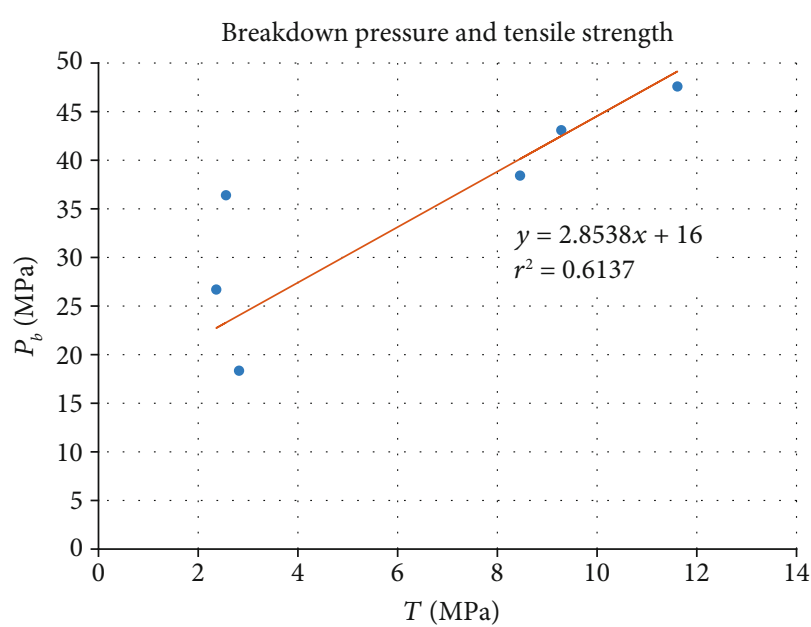

FIgURE 8: Correlation between breakdown pressure and tensile strength for conventional injection tests. The equation is calibrated based on Equation (1).

TABLE 5: Sources of data for the cyclic injection curve fitting (cyclic breakdown pressure/conventional breakdown pressure vs. number of cycles).

\begin{tabular}{lc}
\hline Authors & Rock type \\
\hline Kang et al. [12] & Tight Xujiahe sandstone \\
Kang et al. [12] & Normal Xujiahe sandstone \\
Patel et al. [4] & Tennessee sandstone \\
Goyal et al. [5] & Tennessee sandstone \\
Zhuang et al. [16, 17] & Pocheon granite \\
Diaz et al. [18, 19] & Pocheon granite \\
Stephansson et al. [20] & Pocheon granite \\
Liang et al. [21] & Concrete \\
Tariq et al. [8] & Concrete \\
\hline
\end{tabular}

stress parameters for a cylindrical specimen under the timevarying axial stress $\sigma(t)$.

As shown in Figure 11, the stress parameters:

$$
\begin{aligned}
\Delta \sigma & =\sigma_{\max }-\sigma_{\min }, \\
\sigma_{a} & =\frac{\Delta \sigma}{2}, \\
\sigma_{m} & =0.5\left(\sigma_{\max }+\sigma_{\min }\right),
\end{aligned}
$$

are defined as the stress range, the loading stress amplitude, and the mean stress, respectively.

For metals, if the stress amplitude $\sigma_{a}$ is less than the yield strength $\sigma_{y}$, the fatigue process is defined as high-cycle fatigue. Basquin [22] observed that the $\sigma_{a}$ versus $N_{f}$ (the number of cycles required for fatigue failure) data can be effectively linearized on the $\log -\log$ axis. The empirical equation is defined as

$$
\sigma_{a}=\sigma_{f}^{\prime}\left(2 N_{f}\right)^{b}
$$




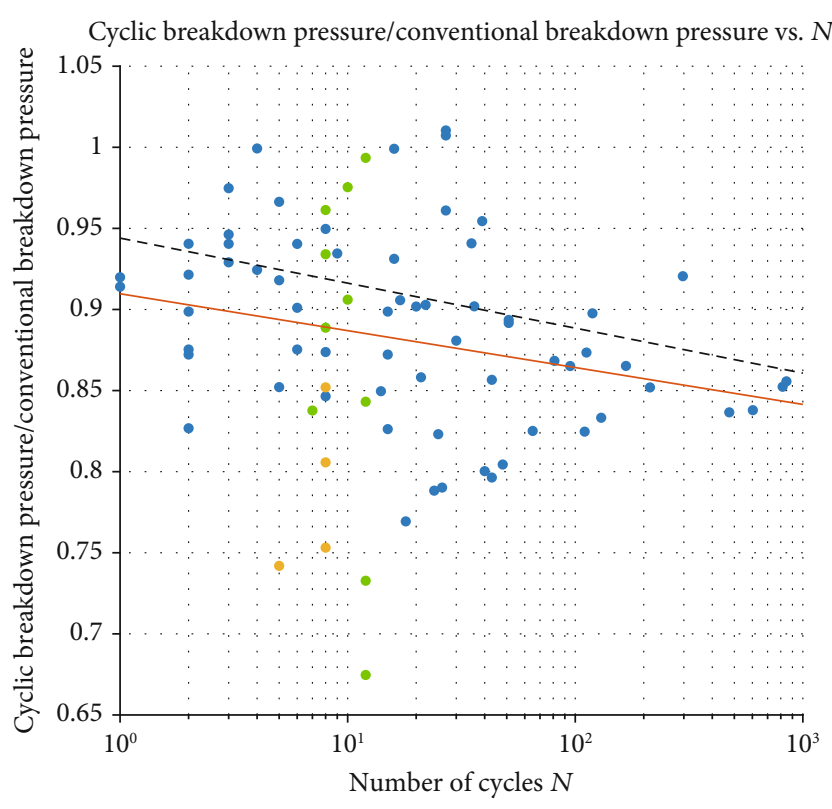

- Data from granite - Data from sandstone

Line fitted from granite, sandstone and concrete data

- Data from concrete

Figure 9: Normalized breakdown pressure (cyclic breakdown pressure/conventional breakdown pressure) versus the number of cycles $N$.

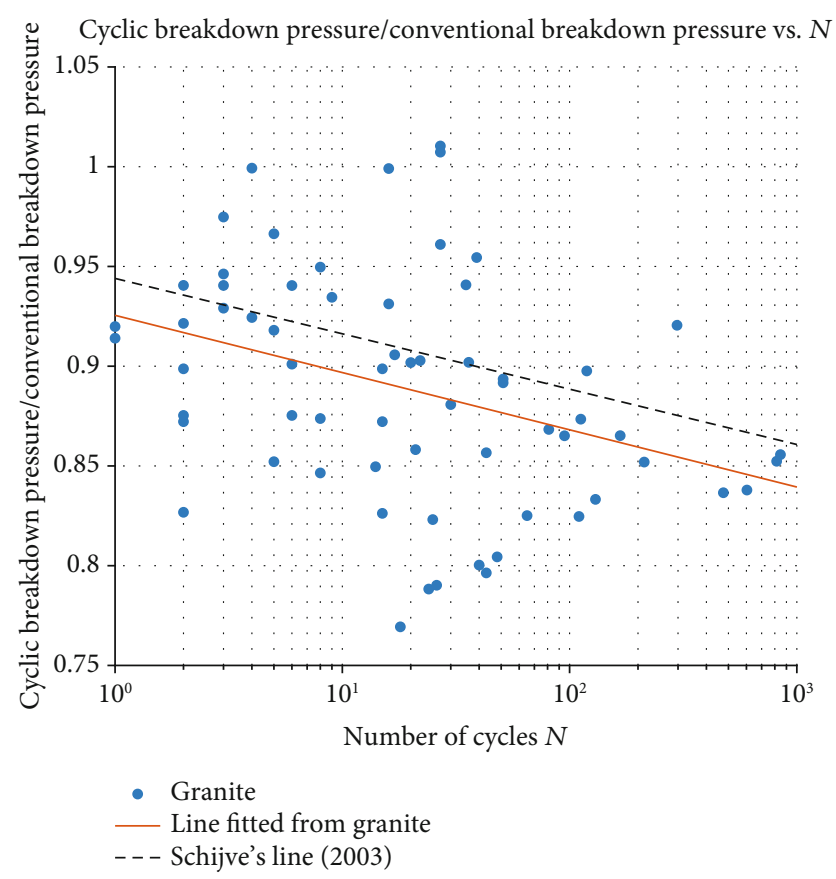

Figure 10: Normalized breakdown pressure (cyclic breakdown pressure/conventional breakdown pressure) versus the number of cycles $N$.

where $b$ and $\sigma_{f}^{\prime}$ are empirically fitted parameters, which are called the fatigue strength exponent and the fatigue strength, respectively. Figure 12 illustrates the concept of the $\sigma_{a}$ versus $N_{f}$ curve.
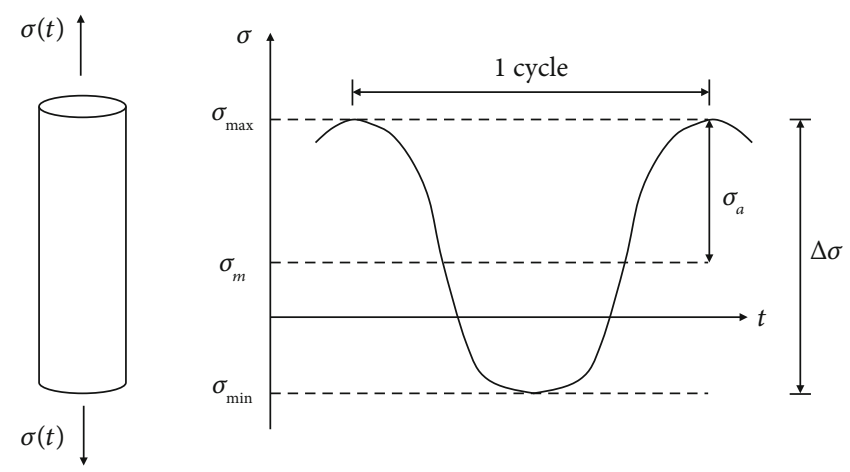

FIgURE 11: Illustration of the stress parameters for a cylindrical specimen under the time-varying axial stress $\sigma(t)$.

For cyclic injection tests in rock, Equation (6) can be modified as

$$
\frac{P_{a}}{P_{\text {con }}}=a\left(N_{f}\right)^{b}
$$

where $P_{a}$ is the injection pressure amplitude, $N_{f}$ is the number of required tests until failure, and $a$ and $b$ are curve-fitted parameters. In this research, only the results with the same injection pressure between different cycles (constant pressure injection method) were analyzed. The injection pressure amplitude is defined as

$$
P_{a}=\frac{\left(P_{\text {max-inj }}-P_{\text {min-inj }}\right)}{2},
$$

where $P_{\max -i n j}$ is the maximum injection pressure and $P_{\text {min-inj }}$ is the minimum injection pressure. Since the amount of data for sandstone and concrete is very limited, the data analysis for granite will be reported. Figure 13 summarizes the $P_{a} / P_{\text {con }}$ versus $N_{f}$ relationship for granite, and the relationship can be expressed as

$$
\frac{P_{a}}{P_{\text {con }}}=0.4258\left(N_{f}\right)^{-0.01909} .
$$

Although the data points in Figure 13 are scattered $\left(r^{2}=0.09\right)$, there is a visible trend. The $P_{a} / P_{\text {con }}$ decreases with $N_{f}$, which indicates that if the injection pressure amplitude increases, a smaller number of cycles are required to achieve the formation breakdown.

It is also worth noting that between different points, the injection pressure, injection frequency, and confining pressure are different. In the future, if there are more data available, we could further fix some of the above-mentioned experimental parameters (e.g., confining pressure) to reduce the data scattering.

4.3. Loading Stress Amplitude at Each Cycle versus the Number of Cycles for Dry Cyclic Tests. Similar to Section 2, we also summarize some results for dry cyclic tests. We select 


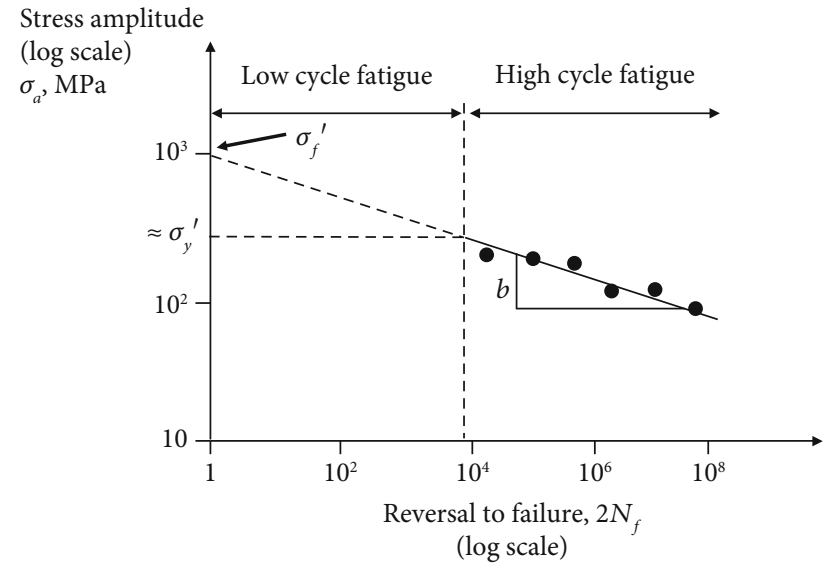

Figure 12: Illustration of the $\sigma_{a}$ versus $N_{f}$ curve [23].

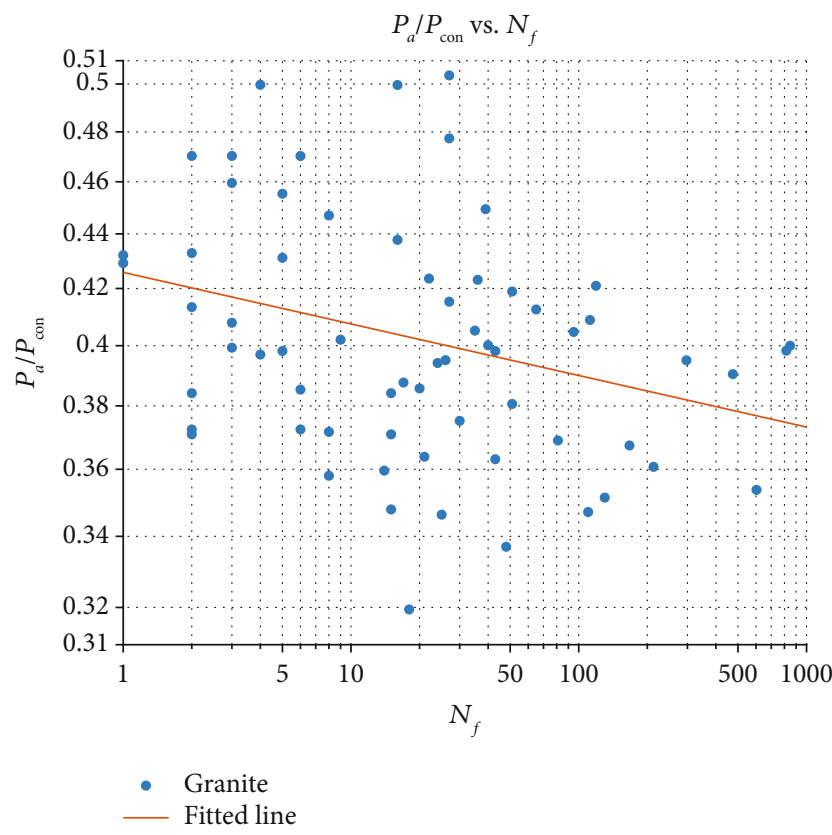

Figure 13: $P_{a} / P_{\text {con }}$ versus $N_{f}$ for cyclic injection tests on granite. The red line is the fitted line.

the results from three papers: Singh [24], Haimson and Kim [25], and Guo et al. [26]. Figure 14 summarizes the $\sigma_{a} / \sigma_{\text {con }}$ versus $N_{f}$ relationship, and the relationship can be expressed as

$$
\frac{\sigma_{a}}{\sigma_{\text {con }}}=0.5443\left(N_{f}\right)^{-0.1098}
$$

Compared to Figure 13, the data points in Figure 14 show less scattering $\left(r^{2}=0.65\right)$. This indicates that, compared with the effect of injection pressure amplitude in cyclic injection tests, the effect of loading stress amplitude on the required number of cycles to fatigue failure may be more significant in dry tests.

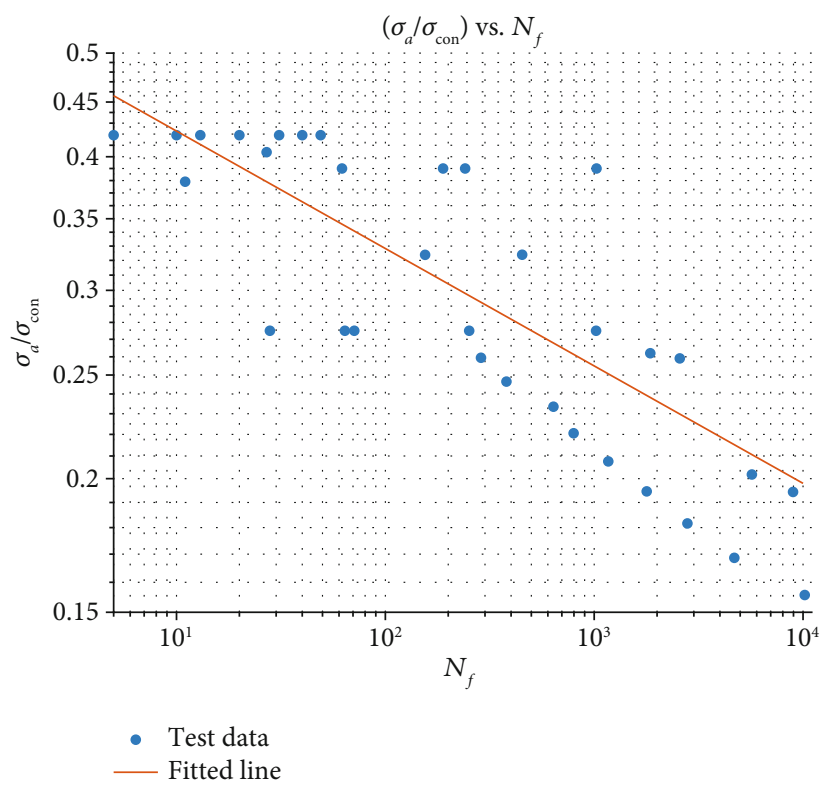

Figure 14: $\sigma_{a} / \sigma_{\text {con }}$ versus $N_{f}$ for dry cyclic tests. The red line is the fitted line.

\section{Conclusions and Recommendations}

Since cyclic injection could reduce the formation breakdown pressure, it is of interest for hydraulic fracturing on reservoir rocks, especially for tight and strong rocks such as the Xujiahe sandstones. This research systematically investigated the effect of cyclic injection on the breakdown pressure of the Xujiahe sandstones. The results indicate that the breakdown pressure can be reduced by cyclic injection in hydraulic fracturing, and the effect of cyclic injection is more significant for stronger and tighter rocks. The average breakdown pressure was reduced by $18.9 \%$ in very tight sandstone and by $7.18 \%$ in normal sandstone. We also empirically related the breakdown pressure for conventional injection tests to the tensile strength. The breakdown pressure increases as the tensile strength increases. The rock tensile strength plays a more important role in the formation breakdown pressure with a rock strength factor of 2.85. This suggests that the breakdown pressure is higher than expected.

In addition, empirical curves for cyclic injections from different experiments, including the data obtained from publications, have been fitted. Based on this analysis, we proposed empirical equations relating the breakdown pressure reduction to the number of injection cycles and the injection pressure amplitude. The empirical equations imply that the breakdown pressure decreases with increasing the number of cycles and the injection pressure amplitude. Therefore, cyclic injection can be used to reduce the breakdown pressure in the field of hydraulic fracturing. To further reduce the breakdown pressure in cyclic injection, the number of cycles or the injection pressure amplitude can be increased.

The experiments also indicate possible future research directions. For the laboratory work, more tests can be conducted to systematically investigate the effect of the number of cycles, injection pressure amplitude, and cyclic frequency 
on the breakdown pressure reduction. To explore the mechanisms of breakdown pressure reduction, acoustic emission or scanning electron microscopy (SEM) can be used to detect the growth of microcracks. For the curve fitting, if more data are available in the future, empirical equations with less data scattering can be fitted by fixing some experimental parameters (e.g., confining pressure and injection frequency). Practically, the current laboratory and curve-fitting results can provide relevant information for breakdown pressure reduction in field hydraulic fracturing operations.

\section{Data Availability}

The data used to support the results of this research are available from the corresponding author upon request.

\section{Conflicts of Interest}

None of the authors have any conflicts of interest.

\section{Acknowledgments}

This research is inspired by the field hydraulic fracturing results from SINOPEC (China Petroleum \& Chemical Corporation). This project is partially supported by the SINOPEC Petroleum Exploration and Production Research Institute.

\section{References}

[1] J. Cai, W. Wei, X. Hu, R. Liu, and J. Wang, "Fractal characterization of dynamic fracture network extension in porous media," Fractals, vol. 25, no. 2, p. 1750023, 2017.

[2] J. Yuan, R. Jiang, and W. Zhang, "The workflow to analyze hydraulic fracture effect on hydraulic fractured horizontal well production in composite formation system," Advances in GeoEnergy Research, vol. 2, no. 3, pp. 319-342, 2018.

[3] G. Zhang, Y. Zhang, A. Xu, and Y. Li, "Microflow effects on the hydraulic aperture of single rough fractures," Advances in GeoEnergy Research, vol. 3, no. 1, pp. 104-114, 2019.

[4] S. M. Patel, C. H. Sondergeld, and C. S. Rai, "Laboratory studies of hydraulic fracturing by cyclic injection," International Journal of Rock Mechanics and Mining Sciences, vol. 95, pp. 8-15, 2017.

[5] S. Goyal, M. E. Curtis, C. H. Sondergeld, and C. S. Rai, "A comprehensive study of monotonic and cyclic injection hydraulic fracturing in saturated tight rocks under triaxial stress," in Proceedings of the Unconventional Resources Technology Conference (URTeC), Austin, TX, USA, 2020.

[6] L. Zhuang, S. G. Jung, M. Diaz et al., "Cyclic hydraulic fracturing of Pocheon granite cores and its impact on breakdown pressure, acoustic emission amplitudes and injectivity," International Journal of Rock Mechanics and Mining Sciences, vol. 122, article 104065, 2019.

[7] A. Zang, G. Zimmermann, H. Hofmann, O. Stephansson, K. Min, and K. Y. Kim, "How to reduce fluid-injectioninduced seismicity," Rock Mechanics and Rock Engineering, vol. 52, no. 2, pp. 475-493, 2019.

[8] Z. Tariq, M. Mahmoud, A. Abdulraheem, D. Al-Shehri, and M. Murtaza, "An environment friendly approach to reduce the breakdown pressure of high strength unconventional rocks by cyclic hydraulic fracturing," Journal of Energy Resources Technology, vol. 142, no. 4, article 043002, 2020.

[9] J. Zhang, H. Zheng, G. Wang et al., "In-situ stresses, abnormal pore pressures and their impacts on the Triassic Xujiahe reservoirs in tectonically active western Sichuan basin," Marine and Petroleum Geology, vol. 123, article 104708, 2020.

[10] B. Cerfontaine and F. Collin, "Cyclic and fatigue behaviour of rock materials: review, interpretation and research perspectives," Rock Mechanics and Rock Engineering, vol. 51, no. 2, pp. 391-414, 2018.

[11] J. Schijve, "Fatigue of structures and materials," Fatigue of Structures and Materials, vol. 25, pp. 679-702, 2003.

[12] H. Kang, X. Fan, Z. Huang, and J. Zhang, "Investigating the effect of cyclic loading on the breakdown pressure of the Xujiahe sandstone," in Proceedings for the 54th US Rock Mechanics/Geomechanics Symposium, Denver, 2020.

[13] Y. Zhang, J. Zhang, B. Yuan, and S. Yin, "In-situ stresses controlling hydraulic fracture propagation and fracture breakdown pressure," Journal of Petroleum Science and Engineering, vol. 164, pp. 164-173, 2018.

[14] J. Zhang, Applied Petroleum Geomechanics, Elsevier, 1st edition, 2019.

[15] B. C. Haimson and C. Fairhurst, "Initiation and extension of hydraulic fractures in rocks," Society of Petroleum Engineers Journal, vol. 7, pp. 310-318, 1967.

[16] L. Zhuang, K. Y. Kim, S. G. Jung et al., "Laboratory evolution of induced seismicity reduction and permeability enhancement effects of cyclic hydraulic fracturing," in Proceedings of the 51st US Rock Mechanics / Geomechanics Symposium, San Francisco, 2017.

[17] L. Zhuang, K. Y. Kim, S. G. Jung et al., "Cyclic hydraulic fracturing of cubic granite samples under triaxial stress state with acoustic emission, injectivity and fracture measurements," in Proceedings of the 52nd US Rock Mechanics/Geomechanics Symposium, Seattle, 2018.

[18] M. Diaz, S. G. Jung, L. Zhuang, and K. Y. Kim, “Comparison of acoustic emission activity in conventional and cyclic hydraulic fracturing in cubic granite samples under tri-axial stress state," in 52nd U.S. Rock Mechanics/Geomechanics Symposium, Seattle, Washington, 2018a.

[19] M. Diaz, S. G. Jung, L. Zhuang et al., "Hydraulic, mechanical and seismic observations during hydraulic fracturing by cyclic injection on Pocheon granite," in Proceedings of the 10th Asian Rock Mechanics Symposium, p. 368, Singapore, 2018.

[20] O. Stephansson, H. Semikova, G. Zimmermann, and A. Zang, "Laboratory pulse test of hydraulic fracturing on granitic sample cores from Äspö HRL, Sweden,” Rock Mechanics and Rock Engineering, vol. 52, no. 2, pp. 629-633, 2019.

[21] T. Liang, B. Guan, Y. Yan, H. Fu, Y. Xu, and Y. Liu, "Laboratory study of hydraulic fracturing in cyclic injection," in Proceedings of the 52nd US Rock Mechanics/Geomechanics Symposium, Seattle, 2018Article ID: 407.

[22] O. H. Basquin, "The exponential law of endurance tests," American Society of Testing Material Proceedings, vol. 10, pp. 625-630, 1910.

[23] L. Anand, Lecture Notes for Introduction to Solid Mechanics, Massachusetts Institute of Technology, 2015.

[24] S. Singh, "Fatigue and strain hardening behaviour of graywacke from the flagstaff formation, New South Wales," Engineering Geology, vol. 26, no. 2, pp. 171-179, 1989. 
[25] B. C. Haimson and C. M. Kim, "Mechanical behavior of rock under cyclic fatigue," Stability of Rock Slopes, Proceedings of the 13th Symposium on Rock Mechanics, E. J. Cording, Ed., , pp. 845-863, ASCE, New York, 1971.

[26] Y. Guo, C. Yang, L. Wang, and F. Xu, "Effects of cyclic loading on the mechanical properties of mature bedding shale," Advances in Civil Engineering, vol. 2018, Article ID 8985973, 9 pages, 2018. 